\title{
1 Oxygen supply limits the heat tolerance of locusts during the first instar only
}

2 Jacob P. Youngblood ${ }^{1 *}$, John M. VandenBrooks ${ }^{2}$, Oluwatosin Babarinde ${ }^{1}$, Megan E. Donnay ${ }^{1}$,

3 Deanna B. Elliott ${ }^{1}$, Jacob Fredette-Roman ${ }^{1}$, and Michael J. Angilletta Jr. ${ }^{1}$

4

$5 \quad{ }^{1}$ School of Life Sciences, Arizona State University, Tempe, AZ 85287, USA

$6 \quad{ }^{2}$ Department of Physiology, Midwestern University, Glendale, AZ 85308, USA

8 *Corresponding author: jpyoungb@asu.edu, 427 East Tyler Mall, LSC 488, Tempe, AZ, 85287

10 Keywords: OCLTT, temperature, hypoxia, survival, ontogeny, heat tolerance

11 Running title: Oxygen limits heat tolerance of locusts 


\section{Abstract}

14 Extreme heat directly limits an organism's survival and reproduction, but scientists cannot agree

15 on what causes organisms to lose function or die during heating. According to the theory of

16 oxygen- and capacity-limitation of thermal tolerance, heat stress occurs when a warming

17 organism's demand for oxygen exceeds its supply, triggering a widespread drop in ATP

18 concentration. This model predicts that an organism's heat tolerance should decrease under

19 hypoxia, yet most terrestrial organisms tolerate the same amount of warming across a wide range

20 of oxygen concentrations. This point is especially true for adult insects, who deliver oxygen

21 through highly efficient respiratory systems. However, oxygen limitation at high temperatures

22 may be more common during immature life stages, which have less developed respiratory

23 systems. To test this hypothesis, we measured the effects of heat and hypoxia on the survival of

24 locusts (Schistocerca cancellata) throughout development. We demonstrate that the heat

25 tolerance of locusts depends on oxygen supply during the first instar but not during later instars.

26 This finding provides further support for the idea that oxygen limitation of thermal tolerance

27 depends on respiratory performance, especially during immature life stages. 


\section{Introduction}

31 Pörtner and colleagues argued that heat tolerance depends on an organism's ability to deliver

32 oxygen during warming (Pörtner 2002; Pörtner et al. 2010), but this idea has been controversial

33 among comparative physiologists (Grans et al., 2014; Jutfelt et al., 2018; Pörtner and Giomi,

34 2013; Pörtner et al., 2017). Recent reviews emphasized that oxygen delivery is just one of many

35 processes that can fail during heat stress; the particular process that fails for an organism will

36 depend on its life history, activity level, and respiratory performance (Clark et al., 2013;

37 Gangloff and Telemeco, 2018; Macmillan, 2019; Schulte, 2015). For example, oxygen supply

38 limits the heat tolerance of aquatic insects more severely than that of terrestrial insects (reviewed

39 by Verberk et al. 2016). This difference arises partly because terrestrial insects live in air, where

40 oxygen is abundant and easy to transport (Giomi et al., 2014; Verberk et al., 2013). However,

41 even air-breathing insects can experience oxygen limitation during immature life stages where

42 oxygen supply depends on a respiratory system that has yet to develop fully (Harrison et al.,

43 2017).

Embryos are arguably the most vulnerable to oxygen limitation, because their oxygen

45 delivery depends on diffusion across the eggshell (Woods, 2010). As temperature rises, an

46 embryo's metabolic demand can increase more quickly than its rate of diffusion (Woods and

47 Hill, 2004). After hatching, larvae still rely on diffusion to deliver oxygen, but it now occurs

48 through the tracheal system, a series of hollow tubes connecting the tissues and atmosphere

49 through spiracles. Diffusion alone can supply the oxygen needed to meet the metabolic demands

50 of small larvae, but larger larvae and adults regulate pressure gradients within the tracheal 
51 system to move oxygen by convection (Weis-Fogh, 1964a; Weis-Fogh, 1964b; Weis-Fogh,

52 1967). For instance, grasshoppers (Schistocerca americana) generate convective airflow with

53 abdominal muscle contractions that repeatedly compress and expand the tracheae (Harrison et al.

54 2013). Grasshoppers use abdominal pumping to enhance oxygen delivery during metabolic

55 challenges such as heat, hypoxia, or activity (Harrison et al., 2006; Lighton and Lovegrove,

56 1990; Snelling et al., 2017), but this ventilatory response does not develop until the third instar

57 (Greenlee and Harrison, 2004a; Lee et al., 2013). Therefore, oxygen delivery becomes easier as

58 grasshoppers advance from instar-to-instar. (Greenlee and Harrison, 2004b; Greenlee et al.,

59 2009; Harrison et al., 2005; Hartung et al., 2004; Kirkton et al., 2005; Lease et al., 2006). If the

60 heat tolerance of a grasshopper depends on its capacity to deliver oxygen, these ontogenetic

61 changes in ventilation should make them more susceptible to heat and hypoxia during early life

62 stages.

Previously, researchers found that some life stages are more susceptible to heat and

64 hypoxia than others. For example, larval beetles (Tenebrio molitor) died from heat stress $10 \%$

65 faster in hypoxia than normoxia, but adult beetles died at the same rate in either oxygen

66 concentration (Mccue et al., 2015). Similarly, hypoxia reduced the heat tolerance of silk moth

67 larvae (Bombyx mori) but not that of pupae (Boardman et al., 2015). Verberk and colleagues

68 (2013) proposed that such discrepancies stem from different ways that organisms acquire

69 oxygen; organisms that can upregulate oxygen delivery as supply increases should tolerate heat

70 and hypoxia better than organisms that cannot. To test this hypothesis, we measured the effects

71 of heat and hypoxia on the survival and development of South American locusts (Schistocerca

72 cancellata) from hatching to adulthood and from the beginning to end of the $1^{\text {st }}, 3^{\text {rd }}$, and $5^{\text {th }}$

73 instars. We predicted that heat and hypoxia would interact to kill more locusts than heat and 
74 hypoxia alone, especially during the $1^{\text {st }}$ instar when oxygen delivery depends primarily on 75 diffusion.

\section{Materials and methods}

Locusts were obtained from a breeding colony at Arizona State University, established from a

79 sample of more than 1000 individuals, collected near Casa de Piedras of Argentina in 2015

80 (Medina et al., 2017). Locusts were housed in an aluminium-framed screen cage (45 x 45 x 45

$81 \mathrm{~cm}$ ) within an environmental chamber (Conviron, Winnipeg, Canada) programmed to control

82 light and temperature. The light cycle was $14 \mathrm{~L}: 10 \mathrm{D}$, and the temperatures were $35^{\circ} \mathrm{C}$ during the

83 day and $25{ }^{\circ} \mathrm{C}$ at night. A 75-watt infrared lamp generated heat for behavioural thermoregulation.

84 Locusts were fed an excess of lettuce, wheat bran, and wheat grass daily. During the

85 experiments, locusts were housed individually in plastic cups $(946 \mathrm{~mL})$ with a perch to facilitate

86 molting. We supplied fresh food daily and removed uneaten food and frass every other day.

For the first experiment, we collected 96 locusts from the colony on the first day of their

88 first instar. We reared these locusts from hatching to adulthood in one of four treatments: cold

89 and normoxic (a diel cycle of $21^{\circ}-35^{\circ} \mathrm{C}$ and $21 \% \mathrm{O}_{2}$ ); hot and normoxic (a diel cycle of $28^{\circ}$ -

$9042^{\circ} \mathrm{C}$ and $21 \% \mathrm{O}_{2}$ ); cold and hypoxic (a diel cycle of $21^{\circ}-35^{\circ} \mathrm{C}$ and $13 \% \mathrm{O}_{2}$ ); and hot and

91 hypoxic (a diel cycle of $28^{\circ}-42^{\circ} \mathrm{C}$ and $13 \% \mathrm{O}_{2}$ ). To control atmospheric oxygen, we put the

92 containers of locusts in each treatment into a chamber $(60$ x 45 x $37 \mathrm{~cm}$; SKU\# 1006267, The

93 Container Store, USA). The atmosphere in each chamber was regulated by a ROXY-4 Universal

94 Controller (Sable Systems International, Las Vegas, NV, USA). To control temperature, each

95 chamber was placed in an incubator (DR-36VL; Percival Scientific, Perry, Iowa, USA), 
96 programmed to maintain the diel cycle of temperature. We recorded daily survival, the time to

97 reach the 2 nd instar, and the time to reach adulthood.

We repeated the experiment with locusts collected at the beginning of the third instar and

99 locusts collected at the beginning of the fifth instar ( $\mathrm{N}=65$ and $\mathrm{N}=40$, respectively). These

100 locusts were followed until their next instar. We recorded daily survival and time to next instar.

101 Locusts were scored as surviving to the next instar if they were alive 24 hours after molting.

We fit three statistical models to the data using the R statistical software (version 3.4.1; R

103 Core Team 2017). First, we modeled the probability of locusts surviving specific instars in each

104 treatment. To do so, we used the nlme library to fit a generalized linear model with a binomial

105 distribution of error and fixed effects of temperature, oxygen, and instar. Second, we modeled

106 the probability of locusts surviving each day, from hatching to adulthood. For this analysis, we

107 used the survival library to fit a Cox proportional-hazards model with effects of temperature and

108 oxygen. Finally, we modeled the development time of locusts during the first, third, and fifth

109 instars. We used the nlme library to fit a generalized linear model with a Gaussian distribution of

110 error and fixed effects of temperature, oxygen, and instar. For each of these analyses, we used

111 the MuMIn library (Bartoń, 2013) to perform multimodel averaging. This package fits a set of

112 models containing all possible subsets of the fixed factors and calculates the weighted average of

113 each parameter value using the likelihood of the full model and all possible subsets of the full

114 model. Model averaging reduces the bias in estimating sources of variation by using all likely

115 models instead of one model with less than full likelihood (Burnham and Anderson, 1998;

116 Harrison et al., 2018). 


\section{Results}

119 A locust's probability of surviving to the next instar depended on its body temperature, oxygen

120 supply, and life stage. As shown in Table 1, the most likely models included main effects of

121 temperature, oxygen, and instar, as well as some interactions between these variables. Based on

122 means estimated by model averaging, third instar locusts would be more than 93\% likely to

123 survive in any treatment (Fig. 1). The probabilities of a locust surviving the third or fifth instar

124 were similar among treatments. However, locusts in the first instar were more susceptible to

125 death under heat and hypoxia. During this early life stage, only $67 \%$ of locusts survived to the

126 next instar in the hot and hypoxic treatment, compared to $90 \%$ or greater survivorship in the

127 other treatments.

128 Survivorship from hatching to adulthood depended on temperature more than oxygen

129 concentration (Table 2). Temperature was included in all likely models, summing to a likelihood

130 of 1 (Table S1). Specifically, locusts died more often in the treatments with higher temperatures

131 (Fig. 2). Only 9 of 42 locusts in the hot treatments survived to adulthood, whereas 20 of 46 in the

132 cold treatments survived to the same stage.

Development time depended on temperature and instar more than oxygen concentration.

134 (Table 3). Temperature, instar, and their interaction were included in all likely models, summing

135 to a likelihood of 1 . Oxygen concentration was less likely to be included in the best model of

136 development time (Table S1). Not surprisingly, locusts of all instars developed faster in the

137 warmer treatment. This effect was greatest during the fifth instar (Fig. 3). Across all treatments,

138 locusts in the fifth instar $(\mathrm{N}=38)$ took longer to develop than did locusts in either the first or

139 third instar $(\mathrm{N}=73$ and 63 , respectively). 


\section{4. Discussion}

142 If oxygen supply limits thermal tolerance (Pörtner, 2002; Pörtner, 2010), locusts should have

143 been most susceptible to heat and hypoxia during the early instars because oxygen delivery

144 becomes easier as locusts develop (Greenlee and Harrison, 2004a; Greenlee et al., 2009;

145 Harrison et al., 2005; Hartung et al., 2004; Kirkton et al., 2005; Lease et al., 2006). As predicted,

146 heat and hypoxia interacted to kill more locusts during the first instar than any other instar (Fig.

147 1). This finding supports the idea that respiratory performance affects an organism's

148 susceptibility to heat and hypoxia. In a closely related species (S. americana), grasshoppers in

149 later instars delivered more oxygen than those in the first instar by ventilating faster and deeper;

150 Greenlee and Harrison (2004a) found that at $35^{\circ} \mathrm{C}$, grasshoppers in the first, third, and fifth

151 instars sustained metabolism down to $13.8,9.9$, and $4.9 \%$ oxygen, respectively. Assuming these

152 ontogenetic patterns hold for S. cancellata, the hypoxia treatment (13\% oxygen) would have

153 limited the metabolism of locusts in the first instar, but this limitation would only have been

154 detrimental at high temperatures. Locusts in the first instars exposed to the cold, hypoxic

155 treatment could have tolerated poor oxygen supply by opening their spiracles for longer or

156 making their tracheolar fluid more permeable to oxygen (Greenlee and Harrison, 1998; Harrison

157 et al., 2006; Wigglesworth, 1983). While this may have been sufficient in cold treatments, we

158 suspect that these compensatory mechanisms were eventually outstripped by the demand for

159 oxygen.

Hypoxia had weak effects on survival and development after the first instar. Locusts in

161 the hypoxia treatment developed at the same rate as those in the normoxia treatment (Fig. 3), 
162 contrasting previous observations of S. americana, which developed more slowly under $10 \%$

163 oxygen than under normoxia (Harrison et al., 2006). Presumably the level of hypoxia in our

164 experiment (13\% oxygen) was not severe enough to impact development. Studies of other insects

165 support the idea that a threshold level of hypoxia reduces performance. For instance, hypoxia

166 influenced the survival and development of mealworm beetles (T. molitor) only when oxygen

167 concentration dropped below 15\% (Loudon, 1988). Similarly, cockroaches (Blatella germanica)

168 reared in an atmosphere of $16 \%$ oxygen developed as quickly as those reared in $21 \%$ oxygen,

169 while lower oxygen levels increased development time (VandenBrooks et al., 2012). Such

170 thresholds reflect the nonlinear nature of hypoxic stress (Harrison et al., 2017; Rascon and

171 Harrison, 2010), but thresholds may depend on interactions between an organism's thermal

172 environment and its developmental stage.

In many species of terrestrial insects, heat tolerance remains the same over a large

174 range of atmospheric oxygen concentrations, presumably because terrestrial insects have highly

175 efficient respiratory systems and occupy an oxygen-rich environment (Klok et al., 2004;

176 Lehmann et al., 2019; McCue and De Los Santos, 2013; Shiehzadegan et al., 2017; Youngblood

177 et al., 2019). However, the function of insects can be limited by oxygen supply during

178 metabolically demanding activities, such as flight. For instance, at $35{ }^{\circ} \mathrm{C}$, the flight metabolic

179 rates of American grasshoppers (S. americana) and migratory locusts (Locusta migratoria)

180 decreased sharply under hypoxia (Rascón and Harrison, 2005; Snelling et al., 2017). If flight

181 performance is limited by oxygen supply, an insect's ability to fly during heat stress may be

182 limited by its capacity to deliver oxygen to its tissues. This hypothesis is supported by a study on

183 fruit flies (Drosophila melanogaster); Teague and colleagues (2017) discovered that a

184 genotype's ability to fly under hypoxic stress depended on its ability to fly under heat stress, 
185 indicating that a common mechanism underlies tolerance to heat and hypoxia. Our findings

186 provide further support for the link between hypoxia tolerance and heat tolerance, more insight

187 into the mechanisms of heat tolerance will come from studying the effects of heat and hypoxia

188 on animals engaged in aerobic activity.

Graham and colleagues (1995) proposed that oxygen delivery is more difficult for

190 larger insects, because diffusion rates decrease as the length of tracheae increase. However,

191 recent evidence suggests that large insects compensate for longer diffusion distances by investing

192 a higher proportion of their body mass into the tracheal system (Kaiser et al., 2007). For

193 example, as grasshoppers (S. americana) grow and develop, tracheal volume scales

194 hypermetrically with body mass, increasing the respiratory capacity of older, larger grasshoppers

195 (Greenlee et al., 2009; Hartung et al., 2004; Lease et al., 2006). This functional relationship

196 could explain why oxygen supply limited the heat tolerance of $S$. cancellata in the first instar

197 more severely than it limited the heat tolerance of later instars. In general, oxygen limitation at

198 high temperatures occurs in life stages that primarily rely on diffusion for oxygen delivery

199 (Woods and Hill, 2004). Indeed, oxygen supply limits the heat tolerance of embryonic lizards

200 (Smith et al., 2015), turtles (Liang et al., 2015), and quails (Vimmerstedt et al., 2019). Given

201 that all species must develop a respiratory system at some stage of the life cycle, future work

202 should focus on early stages where the respiratory system lacks the capacity to deliver oxygen

203 seen later in life. 
We thank Rick Overson, Arianne Cease, and the entire Cease Lab for providing the locusts used

207 in this study.

208

209 Competing interests: No competing interests declared.

210 Funding: This work was supported by Arizona State University’s Graduate and Professional

211 Student Association.

214 Bartoń, K. (2013). MuMIn: multi-model inference, R package version 1.9.13.

Boardman, L., Terblanche, J. S., Blossman-Myer, B. L., Burggren, W. W., Blossman-Myer,

216
(2015). Oxygen safety margins set thermal limits in an insect model system. J. Exp. Biol.

Burnham, K. P. and Anderson, D. R. (1998). Model Selection and Multimodel Inference. 218, 1677-85. Springer Science \& Business Media.

\section{Clark, T. D., Sandblom, E., Jutfelt, F., Alsop, D., Wood, C., Barrionuevo, W. R.,} Fernandes, M. N., Behrens, J., Steffensen, J., Behrens, J. W., et al. (2013). Aerobic scope measurements of fishes in an era of climate change: respirometry, relevance and recommendations. J. Exp. Biol. 216, 2771-82.

225 Frederich, M., Po“rtner, H. O. and Po“rtner, P. (2000). Oxygen limitation of thermal 
tolerance defined by cardiac and ventilatory performance in spider crab, Maja squinado.

227 Gangloff, E. J. and Telemeco, R. S. (2018). High Temperature, Oxygen, and Performance:

228 Insights from Reptiles and Amphibians. Integr. Comp. Biol. 58, 9-24.

229 Giomi, F., Fusi, M., Barausse, A., Mostert, B., Pörtner, H.-O. and Cannicci, S. (2014).

230 Improved heat tolerance in air drives the recurrent evolution of air-breathing. Proc. Biol.

$231 \quad$ Sci. 281, 20132927.

232 Graham, J. B., Dudley, R., Aguilar, N. M. and Gans, C. (1995). Implications of the late

233 palaeozoic oxygen pulse for physiology and evolution. Nature 375, 117-120.

234 Grans, A., Jutfelt, F., Sandblom, E., Jonsson, E., Wiklander, K., Seth, H., Olsson, C.,

235 Dupont, S., Ortega-Martinez, O., Einarsdottir, I., et al. (2014). Aerobic scope fails to

236 explain the detrimental effects on growth resulting from warming and elevated $\mathrm{CO} 2$ in

237 Atlantic halibut. J. Exp. Biol. 217, 711-717.

238 Greenlee, K. J. and Harrison, J. F. (1998). Acid-base and respiratory responses to hypoxia in

239 the grasshopper Schistocerca americana. J. Exp. Biol. 201, 2843-2855.

240 Greenlee, K. and Harrison, J. (2004a). Development of respiratory function in the American

241 locust Schistocerca americana I. Across-instar effects. J. Exp. Biol. 207, 497-508.

242 Greenlee, K. J. and Harrison, J. F. (2004b). Development of respiratory function in the

243 American locust Schistocerca americana II. Within-instar effects. J. Exp. Biol. 207, 497-

244508.

245 Greenlee, K. J., Henry, J. R., Kirkton, S. D., Westneat, M. W., Fezzaa, K., Lee, W.-K. and

246 Harrison, J. F. (2009). Synchrotron imaging of the grasshopper tracheal system: 
morphological and physiological components of tracheal hypermetry. Am. J. Physiol. Integr. Comp. Physiol. 297, R1343-R1350.

Harrison, J. F., Lafreniere, J. J. and Greenlee, K. J. (2005). Ontogeny of tracheal dimensions and gas exchange capacities in the grasshopper, Schistocerca americana. Comp. Biochem. Physiol. - A Mol. Integr. Physiol. 141, 372-380.

Harrison, J., Frazier, M. R., Henry, J. R., Kaiser, A., Klok, C. J. and Rascón, B. (2006). Responses of terrestrial insects to hypoxia or hyperoxia. Respir. Physiol. Neurobiol. 154, 4-

Harrison, J. F., Waters, J. S., Cease, A. J., VandenBrooks, J. M., Callier, V., Klok, C. J., Shaffer, K. and Socha, J. J. (2013). How Locusts Breathe. Physiology 28, 18-27.

Harrison, J. F., Greenlee, K. J. and Verberk, W. C. E. P. (2017). Functional hypoxia in insects $\square$ : Definition, assessment, and consequences for physiology, ecology and evolution. Annu. Rev. Entomol. 63, 303-325.

Harrison, X. A., Donaldson, L., Correa-Cano, M. E., Evans, J., Fisher, D. N., Goodwin, C. E. D., Robinson, B. S., Hodgson, D. J. and Inger, R. (2018). A brief introduction to mixed effects modelling and multi-model inference in ecology. PeerJ 6, e4794.

Hartung, D. K., Kirkton, S. D. and Harrison, J. F. (2004). Ontogeny of tracheal system structure: A light and electron-microscopy study of the metathoracic femur of the American locust,Schistocerca americana. J. Morphol. 262, 800-812. 
limited thermal tolerance: blurring ecology and physiology. J. Exp. Biol. 221, jeb169615.

Kaiser, A., Klok, C. J., Socha, J. J., Lee, W. K., Quinlan, M. C. and Harrison, J. F. (2007). Increase in tracheal investment with beetle size supports hypothesis of oxygen limitation on insect gigantism. Proc. Natl. Acad. Sci. U. S. A. 104, 13198-13203.

Kirkton, S. D., Niska, J. A. and Harrison, J. F. (2005). Ontogenetic effects on aerobic and anaerobic metabolism during jumping in the American locust, Schistocerca americana. $J$. Exp. Biol. 208, 3003-12.

Klok, C. J., Sinclair, B. J. and Chown, S. L. (2004). Upper thermal tolerance and oxygen limitation in terrestrial arthropods. J. Exp. Biol. 207, 2361-70.

Komai, Y. (2001). Gas transport in bumblebee flight. J. Exp. Biol. 204, 2999-3007.

Lease, H. M., Wolf, B. O. and Harrison, J. F. (2006). Intraspecific variation in tracheal volume in the American locust, \&lt;em\&gt;Schistocerca americana\&lt;/em\&gt;, measured by a new inert gas method. J. Exp. Biol. 209, 3476 LP - 3483.

\section{Lee, W.-K., Kirkton, S. D., Pedersen, P., Greenlee, K. J., Socha, J. J. and Eubanks, H. B.} (2013). Hypoxia-induced compression in the tracheal system of the tobacco hornworm caterpillar, Manduca sexta. J. Exp. Biol. 216, 2293-2301.

Lehmann, P., Javal, M. and Terblanche, J. S. (2019). Oxygen limitation is not the cause of death during lethal heat exposure in an insect. Biol. Lett. 15, 20180701.

Liang, L., Sun, B.-J., Ma, L. and Du, W.-G. (2015). Oxygen-dependent heat tolerance and developmental plasticity in turtle embryos. J Comp Physiol B 185, 257-263. 
Lighton, J. and Lovegrove, B. (1990). A Temperature-Induced Switch From Diffusive to Convecttve Ventilation in the Honeybee. J. Exp. Biol. 154,.

Loudon, C. (1988). Development of Tenebrio molitor in low oxygen levels.

Macmillan, H. A. (2019). Dissecting cause from consequence: a systematic approach to thermal limits.

Mccue, M. D., De, R. and Santos, L. (2015). Upper Thermal Limits of Insects Are Not the Result of Insufficient Oxygen Delivery. Source Physiol. Biochem. Zool. 86, 257-265.

McCue, M. D. and De Los Santos, R. (2013). Upper Thermal Limits of Insects Are Not the Result of Insufficient Oxygen Delivery. Physiol. Biochem. Zool. 86, 257-256. locust (Schistocerca cancellata).

Portner, H. O. (2002). Climate variations and the physiological basis of temperature dependent

Portner, H. (2010). Oxygen- and capacity-limitation of thermal tolerance: a matrix for integrating climate-related stressor effects in marine. J. Exp. Biol. 213, 881-893. 
Pörtner, H.-O. and Giomi, F. (2013). Nothing in experimental biology makes sense except in the light of ecology and evolution - correspondence on J. Exp. Biol. 216, 2771-2782. J. Exp. Biol. 216, 4494-5.

Pörtner, H. O. and Knust, R. (2007). Climate change affects marine fishes through the oxygen limitation of thermal tolerance. Science (80-. ). 315, 95-97.

Pörtner, H.-O., Bock, C. and Mark, F. C. (2017). Oxygen- and capacity-limited thermal tolerance: bridging ecology and physiology. J. Exp. Biol. 220, 2685-2696.

Rascon, B. and Harrison, J. F. (2010). Lifespan and oxidative stress show a non-linear response to atmospheric oxygen in Drosophila. J. Exp. Biol. 213, 3441-3448.

Rascón, B. and Harrison, J. F. (2005). Oxygen partial pressure effects on metabolic rate and behavior of tethered flying locusts. J. Insect Physiol. 51, 1193-1199.

Schulte, P. M. (2015). The effects of temperature on aerobic metabolism: towards a mechanistic understanding of the responses of ectotherms to a changing environment. J. Exp. Biol. 218, $1856-1866$.

Shiehzadegan, S., Le Vinh Thuy, J., Szabla, N., Angilletta, M. J. and VandenBrooks, J. M. (2017). More oxygen during development enhanced flight performance but not thermal tolerance of Drosophila melanogaster. PLoS One 12, 1-12.

Smith, C., Telemeco, R. S., Angilletta, M. J., VandenBrooks, J. M., Jr, M. J. A. and VandenBrooks, J. M. (2015). Oxygen supply limits the heat tolerance of lizard embryos. Biol. Lett. 11, 20150113-20150113. 
Flight metabolic rate of Locusta migratoria in relation to oxygen partial pressure in atmospheres of varying diffusivity and density. J. Exp. Biol. 220, 4432-4439.

Teague, C., Youngblood, J. P., Ragan, K., Angilletta, M. J. and Vandenbrooks, J. M. (2017). A positive genetic correlation between hypoxia tolerance and heat tolerance supports a controversial theory of heat stress. Biol. Lett. 13, 1-4. Harrison, J. F. (2012). Impacts of Paleo-Oxygen Levels on the Size, Development, aquatic insects dictates their vulnerability to global warming. Biol. Lett. 9, 20130473. review of current evidence. Comp. Biochem. Physiol. Part A Mol. Integr. Physiol. 192, 6478. with the avian lung.

Weis-Fogh, T. (1964b). Diffusion In Insect Wing Muscle, The Most Active Tissue Known. J. 
350 Weis-Fogh, T. (1967). Respiration and Tracheal Ventilation in Locusts and other Flying Insects.

351 J. Exp. Biol. 47,

352 Wigglesworth, V. (1983). The Physiology of Insect Tracheoles. Adv. In Insect Phys. 17, 85-148.

353 Woods, H. A. (2010). Water loss and gas exchange by eggs of Manduca sexta: Trading off costs 354 and benefits. J. Insect Physiol. 56, 480-487.

355 Woods, H. A. and Hill, R. I. (2004). Temperature-dependent oxygen limitation in insect eggs. J. $356 \quad$ Exp. Biol. 207, 2267-2276.

357 Youngblood, J. P., da Silva, C. R. B., Angilletta, M. J. and VandenBrooks, J. M. (2019).

358 Oxygen Limitation Does Not Drive the Decreasing Heat Tolerance of Grasshoppers during

359 Development. Physiol. Biochem. Zool. 92, 567-572. 
361 Table 1. The most likely models of survival included effects of temperature, oxygen, and instar.

362 Each model predicts the probability of surviving to the next instar. For each model, we report the

363 number of parameters $(k)$, the log likelihood, Akaike information criterion (AIC), and the Akaike

364 weight $(w)$, which is the probability that the model describes the data better than other models

365

\begin{tabular}{|c|c|c|c|c|c|}
\hline Model & $k$ & Log likelihood & AIC & $\triangle \mathrm{AIC}$ & $w$ \\
\hline temp $+\mathrm{O}_{2}+$ instar $+\left(\right.$ temp $\left.\cdot \mathrm{O}_{2}\right)+($ temp $\cdot$ instar $)$ & 8 & -56.7 & 130.2 & 0 & 0.26 \\
\hline temp $+\mathrm{O}_{2}+$ instar $+\left(\right.$ temp $\left.\cdot \mathrm{O}_{2}\right)+($ temp $\cdot$ instar $)+\left(\mathrm{O}_{2} \cdot\right.$ instar $)$ & 10 & -55.2 & 131.6 & 1.42 & 0.13 \\
\hline temp $+\mathrm{O}_{2}+$ instar $+\left(\right.$ temp $\left.\cdot \mathrm{O}_{2}\right)+\left(\mathrm{O}_{2} \cdot\right.$ instar $)$ & 8 & -57.5 & 131.9 & 1.67 & 0.11 \\
\hline temp $+\mathrm{O}_{2}+$ instar $+\left(\right.$ temp $\left.\cdot \mathrm{O}_{2}\right)$ & 6 & -59.7 & 131.9 & 1.68 & 0.11 \\
\hline temp $+\mathrm{O}_{2}+$ instar $+($ temp $\cdot$ instar $)+\left(\mathrm{O}_{2} \cdot\right.$ instar $)$ & 9 & -56.9 & 133.0 & 2.76 & 0.06 \\
\hline temp $+\mathrm{O}_{2}+$ instar $+($ temp $\cdot$ instar $)$ & 7 & -60.6 & 133.1 & 2.85 & 0.06 \\
\hline $\mathrm{O}_{2}+$ instar $+\left(\mathrm{O}_{2} \cdot\right.$ instar $)$ & 6 & -62.7 & 133.7 & 3.50 & 0.04 \\
\hline $\mathrm{O}_{2}+$ instar & 4 & -60.6 & 133.8 & 3.55 & 0.04 \\
\hline temp + instar $+($ temp $\cdot$ instar $)$ & 6 & -62.7 & 134.1 & 3.90 & 0.04 \\
\hline temp $+\mathrm{O}_{2}+$ instar & 5 & -62.1 & 134.6 & 4.36 & 0.03 \\
\hline temp $+\mathrm{O}_{2}+$ instar $+\left(\mathrm{O}_{2} \cdot\right.$ instar $)$ & 7 & -60.0 & 134.6 & 4.41 & 0.03 \\
\hline instar & 3 & -64.3 & 134.8 & 4.64 & 0.03 \\
\hline $\begin{array}{l}\text { temp }+\mathrm{O}_{2}+\text { instar }+\left(\text { temp } \cdot \mathrm{O}_{2}\right)+(\text { temp } \cdot \text { instar })+\left(\mathrm{O}_{2} \cdot \text { instar }\right) \\
+\left(\text { temp } \cdot \mathrm{O}_{2} \cdot \text { instar }\right)\end{array}$ & 12 & -54.5 & 134.9 & 4.71 & 0.02 \\
\hline temp + instar & 4 & -63.7 & 135.7 & 5.45 & 0.02 \\
\hline temp $+\mathrm{O}_{2}+\left(\right.$ temp $\left.\cdot \mathrm{O}_{2}\right)$ & 4 & -64.1 & 136.5 & 6.31 & 0.01 \\
\hline
\end{tabular}


367 Table 2. The most likely model of survival during development included only an effect of

368 temperature. Each model is a Cox proportional-hazard models that predict the probability of

369 survival over time. For each model, we report the number of parameters $(k)$, the log likelihood,

370 Akaike information criterion (AIC), and the Akaike weight (w), which is the probability that the

371 model describes the data better than other models

\begin{tabular}{lccccc}
\hline Model & $k$ & Log likelihood & AIC & $\Delta$ AIC & $w$ \\
\hline temperature & 2 & -204.8 & 411.8 & 0 & 0.56 \\
temperature $+\mathrm{O}_{2}$ & 3 & -204.5 & 413.4 & 1.56 & 0.26 \\
temperature $+\mathrm{O}_{2}+\left(\right.$ temperature $\left.\cdot \mathrm{O}_{2}\right)$ & 4 & -203.8 & 414.1 & 2.26 & 0.18 \\
$\mathrm{O}_{2}$ & 2 & -220.8 & 443.7 & 31.9 & 0 \\
null & 2 & -220.9 & 445.8 & 34.0 & 0
\end{tabular}

372

373 
374 Table 3. Temperature, oxygen, and instar affected development times. For each model, we report

375 the number of parameters $(k)$, the log likelihood, Akaike information criterion (AIC), and the

376 Akaike weight $(w)$, which is the probability that the model describes the data better than other

\begin{tabular}{|c|c|c|c|c|c|}
\hline Model & $k$ & Log likelihood & AIC & $\triangle \mathrm{AIC}$ & $w$ \\
\hline $\begin{array}{l}\text { temp }+\mathrm{O}_{2}+\text { instar }+\left(\text { temp } \cdot \mathrm{O}_{2}\right)+(\text { temp } \cdot \text { instar })+\left(\mathrm{O}_{2} \cdot \text { instar }\right) \\
+\left(\text { temp } \cdot \mathrm{O}_{2} \cdot \text { instar }\right)\end{array}$ & 13 & -209.2 & 446.6 & 0 & 0.36 \\
\hline temp $+\mathrm{O}_{2}+$ instar $+\left(\right.$ temp $\left.\cdot \mathrm{O}_{2}\right)+($ temp $\cdot$ instar $)$ & 9 & -214.3 & 447.6 & 1.05 & 0.22 \\
\hline temp $+\mathrm{O}_{2}+$ instar $+\left(\right.$ temp $\left.\cdot \mathrm{O}_{2}\right)+($ temp $\cdot$ instar $)+\left(\mathrm{O}_{2} \cdot\right.$ instar $)$ & 11 & -212.3 & 448.2 & 1.62 & 0.17 \\
\hline temp + instar $+($ temp $\cdot$ instar $)$ & 7 & -216.9 & 448.5 & 1.95 & 0.14 \\
\hline temp $+\mathrm{O}_{2}+$ instar $+($ temp $\cdot$ instar $)+\left(\mathrm{O}_{2} \cdot\right.$ instar $)$ & 10 & -214.5 & 450.3 & 3.74 & 0.06 \\
\hline temp $+\mathrm{O}_{2}+$ instar $+($ temp $\cdot$ instar $)$ & 8 & -216.8 & 450.5 & 3.92 & 0.05 \\
\hline
\end{tabular}

377 models. 


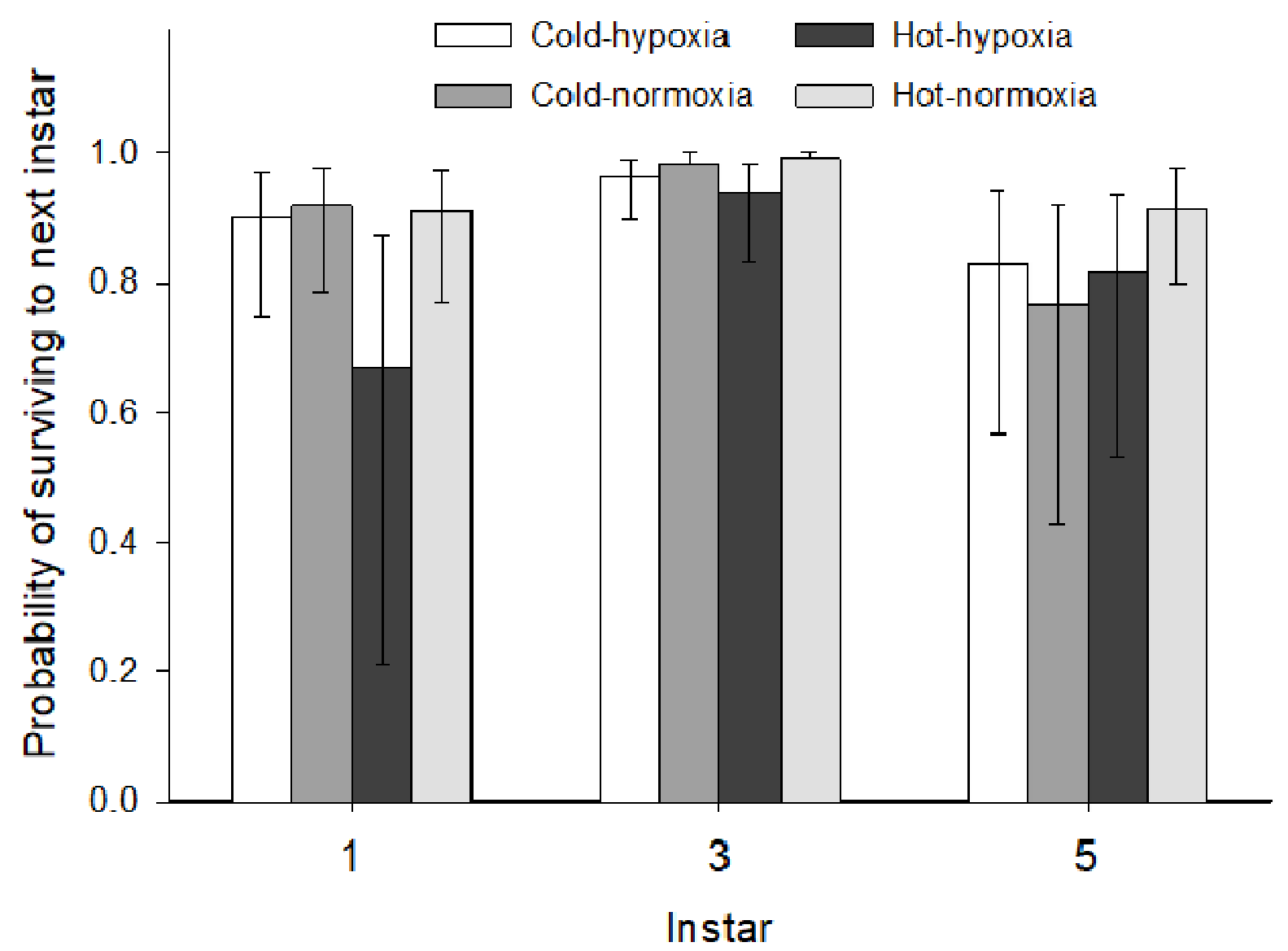

Figure 1. Heat and hypoxia interacted to kill first instar locusts. Bars denote the most likely

382 probability of locusts surviving to the next instar, calculated from multimodel averaging, in cold

383 or hot thermal regimes (21-35 or $28-42{ }^{\circ} \mathrm{C}$, respectively), under either hypoxia or normoxia (13

384 or $21 \%$ oxygen, respectively). Error bars represent $95 \%$ confidence intervals. 


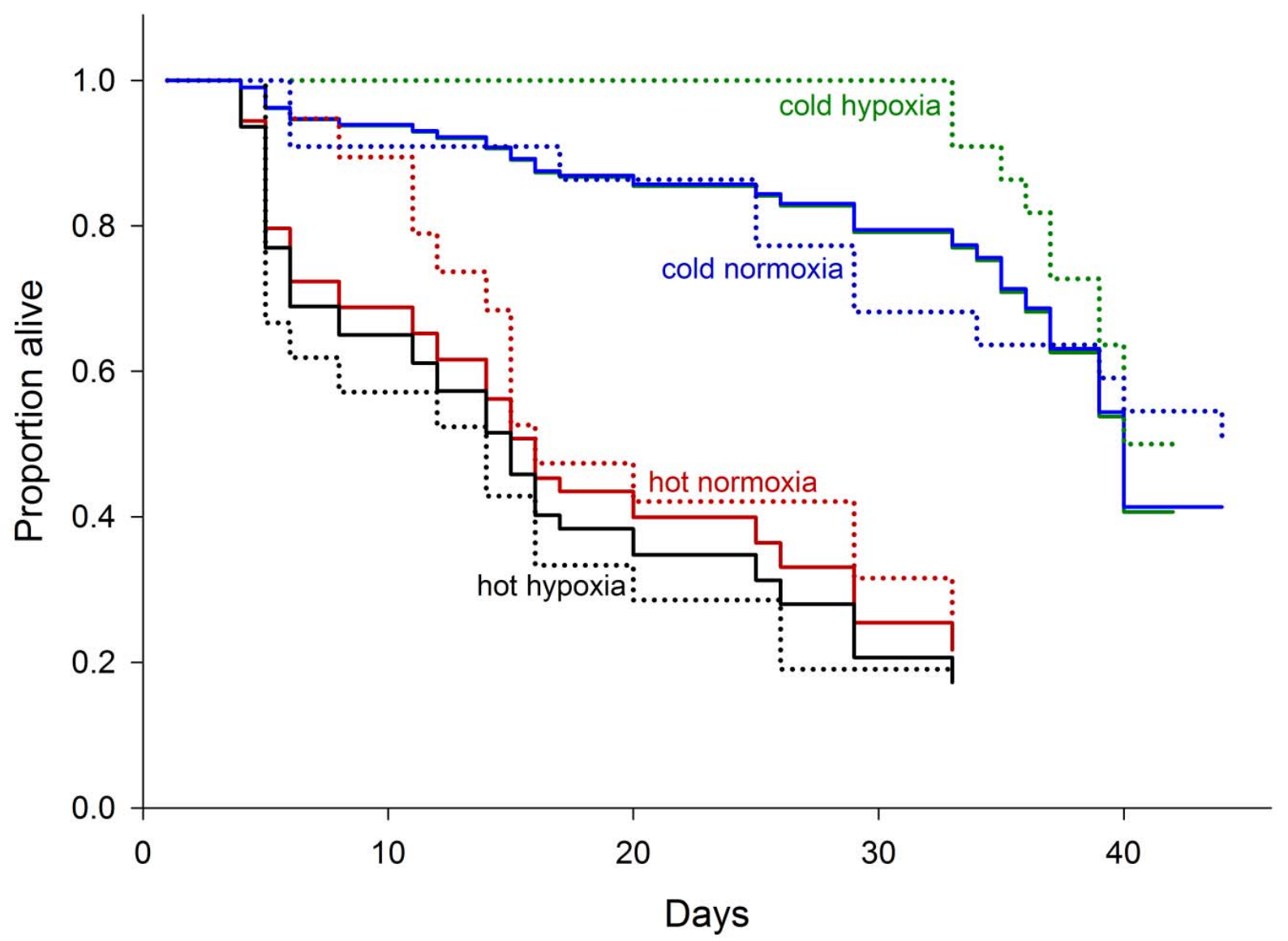

Figure 2. Locusts are more likely to die at high temperatures. Dotted lines denote the proportion

387 of locusts that were alive each day of the experiment. Solid lines denote the most likely

388 probability of a locust surviving each day, calculated from multi-model averaging, in cold or hot

389 thermal regimes (21-35 or $28-42{ }^{\circ} \mathrm{C}$, respectively) under either hypoxia or normoxia (13 or $21 \%$

390 oxygen, respectively). 


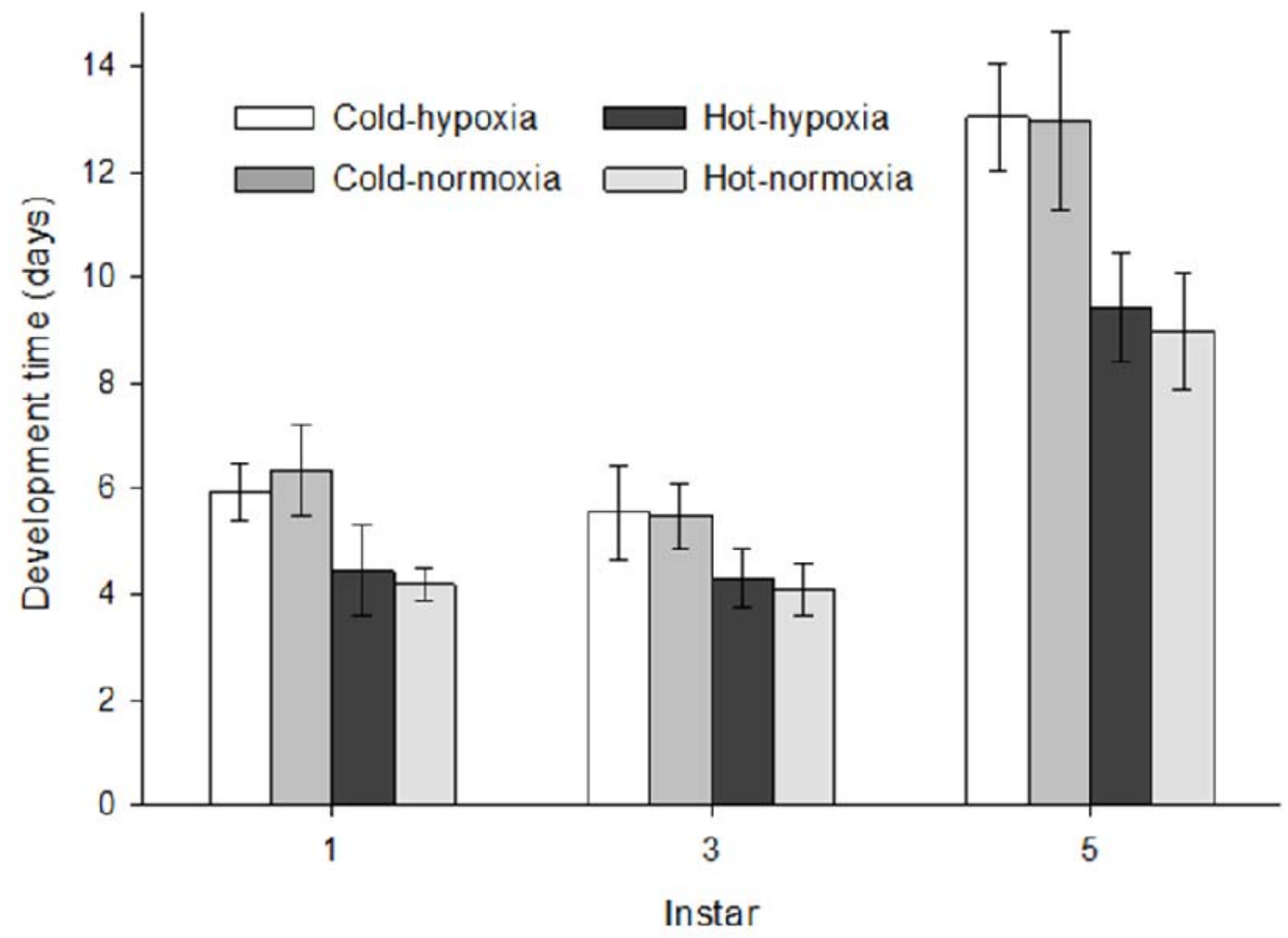

394 Figure 3. Locusts developed faster at high temperatures. Bars denote the most likely mean of

395 development time, calculated from multimodel averaging, for locusts reared in cold or hot

396 thermal regimes (21-35 or $28-42{ }^{\circ} \mathrm{C}$, respectively) under either hypoxia or normoxia (13 and

$39721 \%$ oxygen, respectively). Error bars represent $95 \%$ confidence intervals. 